\section{The world of testable truths}

\section{On Science}

by Brian Ridley

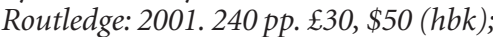

$£ 7.99, \$ 12.95$ (pbk)

\section{John Casti}

What is scientific knowledge? In what way does it differ from any other type of knowledge? Are there logical limits to the kind of knowledge we can acquire about the world around us by employing the methods and procedures of science? For that matter, what is science itself? These are the types of questions that physicist Brian Ridley addresses in this thought-provoking and well-written volume.

The book opens by reminding us of the crucial fact that there are many types of truths, of which the testable truths of science stand beside the revealed truths of religion, the persuasive truths of the humanities and the demonstrable truths of mathematics. Ridley then asserts that there is yet another kind of truth, which he defines as "magical truth". This is a kind of truth that is complementary to that of science - one associated with the non-material, human forces in the world. Poetry, music and the fine arts are examples of where these magical truths reside. Such truths are the domain of the magus, and not the scientist, who is focused on the recurrent in the world, not the unique. This juxtaposition of science and magic is a theme woven throughout the book.

Taking up E. O. Wilson's view of science as an enterprise that gathers knowledge and condenses it into testable laws and principles, the author raises several objections to the idea of a scientific "Theory of Everything' that could - even in principle - answer all the questions we might pose about the world. First, there is the limiting fact that quantum theory, our best scientific theory thus far, involves the inherent uncertainty associated with any measurement of a physical system. Next comes the self-referential fact that the very tools we use to probe nature are themselves part of nature. And finally there is the most serious limitation of all, science's inherent inability to cope with anything unique sometimes labelled 'origins problems'. As science is in the business of addressing recurrent phenomena, it's a debatable matter as to whether questions about the origin of the Universe, life, language, humanity or anything else should even

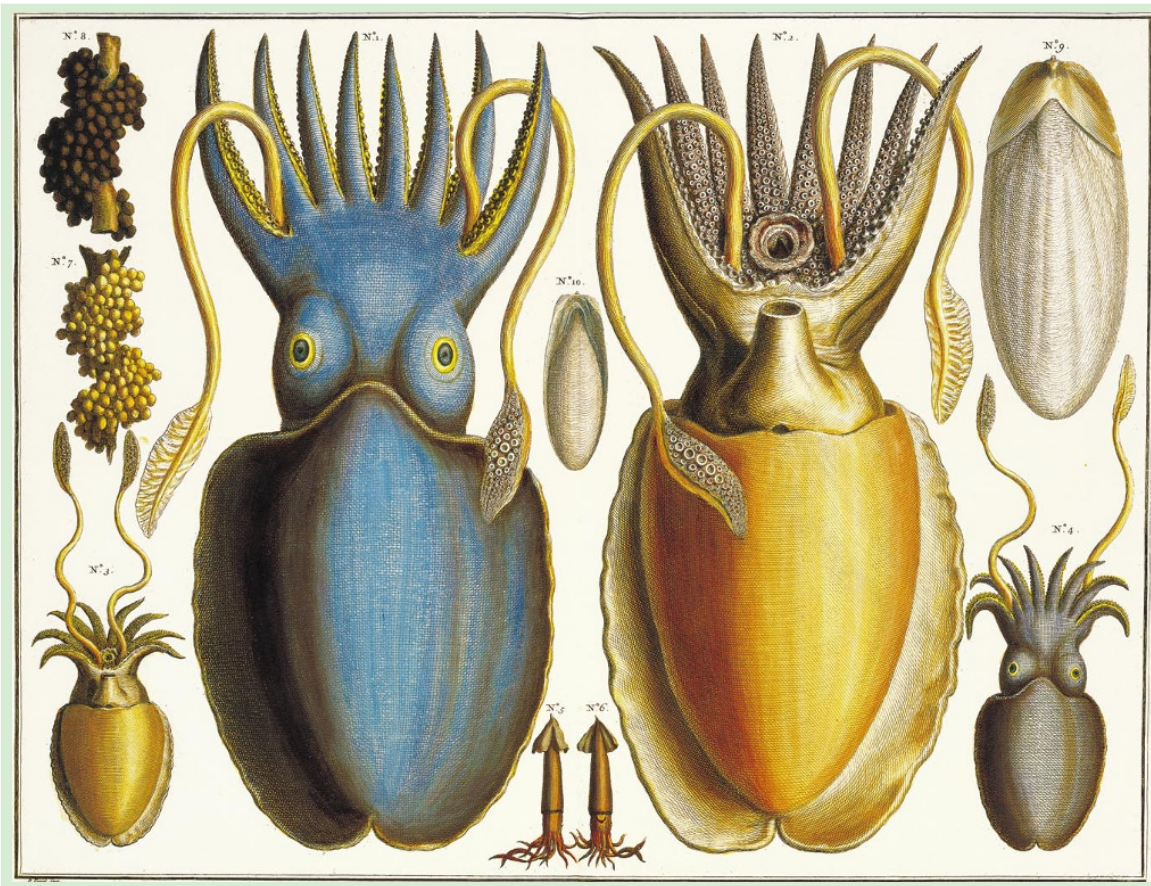

\section{Oddities from the cupboard}

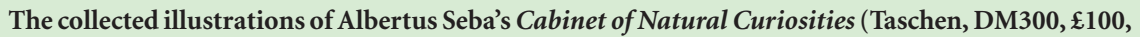
$\$ 150$ ) were first published in the early eighteenth century. Seba's 'curiosities' comprise the exotic species he bought from sailors and travellers returning to the ports of Holland. It was the heyday of exploration, and the beginning of trade between continents. Taschen has republished the illustrations in a luxurious edition of astonishing beauty. The book also includes essays in English, German and French. (Cabinet of Curiosities/Das Naturalienkabinett/Le Cabinet des curiosités naturelles d'Albertus Seba.) be considered a question within the purview of science.

The realm of mathematical truths is the one indisputable place where we can probably pose questions that cannot be answered using the normal modes of mathematical argumentation. The Gödel Incompleteness Theorem ensures that this is the case: it states that in any consistent logical system, there are statements that can be made which can be neither proved nor disproved within the framework of that system. The linkage between this realm and that of the physical world of quarks, planets and billiard balls is crucial for understanding the limits to science. Ridley provides an excellent introduction to these matters.

From mathematics to mind is but a small leap in Ridley's odyssey. The bridge is the long-running controversy between philosophers and computer scientists over the possible existence, even in principle, of a computing machine that could think just like you and me.

Gödel's theorem makes its appearance here again as part of the book's account of Roger Penrose's well-known — and perhaps equally well-criticized - arguments against the protagonists of 'strong' artificial intelligence (AI). Ridley clearly favours the anti-AI camp's position that a thinking machine is essentially a contradiction in terms, and that thought, human-style, is just that: human-style. Period.

The final part of the book is in many ways the least interesting, mainly comprising an assortment of fairly obvious observations about the interface of science both with the humanities and with society in general. The fact that science cannot answer questions about ethics, art or religion is hardly news. Neither is the fact that the gap separating literature and science can be bridged only by recognizing the complementary aspects of science and art. So although one can certainly applaud the author for re-emphasizing these well-known facts, they hardly merit much attention.

But this is a minor quibble, and one cannot ask for miracles in a 200-page volume covering such a broad spectrum of themes and issues. On balance, this is an excellent introduction to a number of important questions residing at that interface where philosophy borders on science, and science becomes philosophical. One can only hope that the author may one day write a sequel, in which the issue of the limits to scientific knowledge will be addressed in much more detail, complete with examples of how one might identify those questions that are beyond the bounds of scientific reasoning — and why!

John Casti is at the Institute of Econometrics, Operational Research and System Theory, Technical University of Vienna, Argentinierstrasse 8, A-1040 Vienna, Austria. 